\title{
A CONSIDERAÇÃO DO GÊNERO COMO DIREITO FUNDAMENTAL À SEGURANÇA NO TRABALHO
}

\section{Marcelo Lucca ${ }^{1}$ \\ Vívian De Gann dos Santos ${ }^{2}$}

\begin{abstract}
RESUMO: A consideração do gênero como perspectiva de análise do ambiente do trabalho visa modificar as abordagens adotadas na implantação de medidas protetivas à segurança e à saúde das mulheres, pois adota-se um viés simplificador de proteção à maternidade ou à alegada fragilidade da mulher. Utilizando-se o método dedutivo, pretende-se inserir uma perspectiva de gênero na consideração das medidas que garantem saúde e segurança no trabalho, pela apresentação de elementos que discutem a necessidade de concessão de tutela diferenciada às mulheres trabalhadoras, bem como do resultado finalístico de tal proteção, verificando se promovem igualdade ou discriminação.
\end{abstract}

Palavras-chave: Direito do Trabalho; Segurança do Trabalho; Ambiente de Trabalho; Gênero; Discriminação.

\section{THE CONSIDERATION OF THE GENDER AS A FUNDAMENTAL RIGHT TO SAFETY AT WORK}

\begin{abstract}
The consideration of gender as a perspective of analysis of the work environment aims to modify the approaches adopted in the implementation of protective measures to the safety and health of women, since a simplistic bias is adopted to protect maternity or the alleged fragility of women. Using the deductive method, it is intended to insert a gender perspective in the consideration of measures that guarantee health and safety at work, by presenting elements the need to grant differentiated protection to working women, as well as the final result of such protection, verifying whether they promote equality or discrimination.
\end{abstract}

Keywords: Labor Law; Labor Safety; Work Evironment; Gender; Discrimination.

\footnotetext{
1 Mestrando no Programa de Pós-Graduação em Direito da Uniritter. Gradução em Direito (UNISINOS) e Engenharia Civil (IPA). Especialista em Engenharia de Segurança do Trabalho (IPA). Master em Prevenção de Riscos (Universidad de Sevilla). Professor do Centro Universitário Metodista do IPA. Servidor do TRT da $4^{\mathrm{a}}$ Região. E-mail: mlucca@trt4.jus.br

2 Mestranda no programa de Pós-Graduação em Direito da Universidade Federal de Santa Catarina (UFSC). Especialista em Direito e Processo do Trabalho pelo Complexo de Ensino Superior de Santa Catarina (CESUSC), com graduação em Direito pela Universidade do Vale do Itajaí (UNIVALI). Advogada e professora da Universidade do Vale do Itajaí (UNIVALI). E-mail vivian@ degann.com.br
} 


\section{INTRODUÇÃO}

Foi na década de 1930 que, no Brasil, o Direito do Trabalho obteve relevância jurídica, pois é a partir dali que as políticas públicas estatais voltaram-se à industrialização do país e tomaram contornos de proteção social - situação que gerou grande impacto sobre a produção legislativa ligada a esta esfera do direito (CRIVELLI, 2017. p. 165-182). Proliferaram-se as leis que versavam sobre direitos dos trabalhadores, cujo ápice ocorreu em 1943, com o Decreto-Lei n. 5.452 (BRASIL, 1943), o qual aprovou a Consolidação das Leis do Trabalho - CLT.

Ganha relevo então a doutrina jurídica do Direito do Trabalho, marcada por seu viés protecionista do trabalhador. Não sem razão, o mais relevante princípio do Direito do Trabalho, até os dias atuais, é o princípio da proteção, o qual afasta-se de qualquer ideal de igualdade formal e concede proteção especial ao obreiro, parte considerada hipossuficiente dentro da relação de trabalho (RODRIGUEZ, 2000. p. 35).

Porém, sempre que se aborda a temática da tutela jurídica do meio ambiente de trabalho em condições seguras e com salubilidade, ressalta-se em primeiro plano a busca pela proteção da força de trabalho ante riscos de acidentes graves, como por exemplo, os riscos existentes na construção civil, na exploração de minérios ou indústrias pesadas, ou seja, pensa-se em trabalhadores do gênero masculino como os únicos (ou principais) destinatários das tarefas laborais perigosas e insalubres, popularmente chamados de trabalhos pesados.

Desta forma, o trabalho dito feminino fica afastado daquele chamado pesado e eminentemente masculino. Consequentemente, a identificação e prevenção aos riscos que poderiam atingir as mulheres trabalhadoras são praticamente invisíveis na área da saúde e segurança do trabalho, a qual persiste "focalizando grupos ocupacionais majoritariamente masculinos" (CORRÊA, 2002. p. 357-388).

Assim, compreender tais questões exige o emprego do gênero como categoria de análise do meio ambiente do trabalho, o que possibilita romper com a abordagem da saúde das mulheres trabalhadoras estritamente na perspectiva da maternidade ou da fragilidade física, de modo a evidenciar a esfera da subjetividade como aspecto fundamental para a promoção da qualidade de vida e consequente equilíbrio entre saúde e trabalho (OLIVEIRA, 2000). 
Diante desse contexto, o presente artigo procura elucidar duas questões que entende importantes: a segurança e a saúde das mulheres no trabalho estão adequadamente protegidas pela legislação em vigor? As normas vigentes promovem igualdade ou discriminação?

No primeiro tópico, será abordado o conceito de meio ambiente do trabalho a partir de sua construção histórica, que tem por marco inicial a Revolução Industrial, a fim de elucidar aspectos da origem da proteção à integridade física do trabalhador, bem como de demonstrar que a igualdade entre trabalhadores e trabalhadoras é eixo fundamental para que exista equilíbrio no espaço de trabalho.

O segundo tópico apresentará algumas bases teóricas que explicam as relações de gênero, a opressão das mulheres, e a consequente construção histórica da divisão sexual do trabalho, como base material da relação de poder entre os gêneros.

Por fim, no último tópico, pretende-se delinear a influência do gênero sobre os riscos ocupacionais, mediante uma análise das especificidades do trabalho das mulheres na contemporaneidade.

Quanto aos aspectos metodológicos, ressalta-se que este trabalho utiliza como método de abordagem o dedutivo.

\section{O AMBIENTE DE TRABALHO E AS GARANTIAS À SAÚDE E À SEGURANÇA DO TRABALHADOR}

Há precedentes históricos que confirmam que a partir do aparecimento do homem e sua relação com o trabalho, sente-se a necessidade de defender a saúde ameaçada pelo risco das atividades realizadas. A evolução tecnológica apresenta-se com grande importância para a melhoria das condições de trabalho. Entretanto, no que se refere à segurança, esses efeitos nem sempre são significativos. Embora haja subnotificação, os dados das taxas de acidentes não indicam uma expressiva redução na atualidade (CORTES, 2007. p. 39).

Não é difícil encontrar referências que recuperem esse histórico. Os efeitos do chumbo em mineração e metalurgia, ou a proteção dos trabalhadores contra o meio ambiente pulvígeno já eram citados por Hipócrates e Plínio, nos séculos II AC e I, respectivamente. Esses eventos históricos iniciais, com especial referência às doenças 
profissionais e suas técnicas de prevenção, delineavam como uma disciplina técnica a medicina do trabalho e a prevenção. Nesta breve viagem histórica, passamos pelo século XVI, onde há textos de Filippus Georgius Agricola e Paracelsus, que descrevem as doenças e os sistemas de proteção e, posteriormente, do século XVIII, quando Ramazzini publicou um tratado sobre as doenças dos artesãos, que abarcou um grande número de profissões da época e as condições de higiene recomendadas (ventilação, temperatura, vestuário, etc), o qual the valeu ser considerado como o pai da medicina do trabalho (CORTÉS, 2007. p. 40).

Apesar dessas citações, o verdadeiro significado de segurança (e higiene) do trabalho pode-se dizer que somente nasceu na Revolução Industrial. Ali, com a invenção da máquina a vapor de James Watt, teve-se como consequência o aumento substancial de fábricas e do número de acidentes, sem o correspondente progresso em adoção e desenvolvimento de técnicas para evitá-los. A situação tornou-se tão caótica naquele tempo, face a alta demanda de trabalho e o surgimento de invenções notáveis como a lançadeira voadora, a fiação, o tear e outros na indústria têxtil, para citar exemplos, ao passo que alguns problemas foram na verdade potencializados. Cortés (2007) destaca em particular a questão das crianças que trabalhavam em condições insalubres, 14 ou 15 horas por dia, conforme descrito por Engels (1844), ao relatar a situação em Manchester City, onde as máquinas aumentaram continuamente sua potência e velocidade, criando riscos maiores.

Nessa época de euforia da Revolução Industrial, como não poderia ser de outra forma, o trabalhador era considerado o único culpado do acidente, recaindo a responsabilidade sobre o empregador apenas quando houvesse total abandono do seu empregado. Até o século XIX não houve medidas efetivas como a criação de inspeções da fábrica. No contexto histórico surge na Inglaterra a Lei das Fábricas, estendendo-se a outros países, que tinha intenção de evitar acidentes em fábricas, mas isto não ocorreu conforme o necessário (CORTES, 2007. p. 39-40).

Somente no início do próximo século, quando os conceitos de segurança e higiene começam a ficar importantes, motivado pela criação da Organização Internacional do Trabalho (OIT), em 1918, e do seu serviço de segurança e prevenção de acidentes em 1921, há a grande contribuição que levou a formação da chamada Escola Americana de Segurança de Trabalho com os seus grandes representantes Heinrich, Simonds, Grimaldi, 
Bird, autores de uma filosofia de segurança, que formou a base da concepção atual da questão (CORTES, 2007. p. 40-41).

Assim, o Estado somente após muitos anos, em que deixou que vigorasse o livre arbítrio na relação entre empregados e empregadores, passou a estabelecer os parâmetros do desempenho do trabalho e as condições de contraprestação. Assim, viu-se obrigado a intervir na relação laboral, por meio da edição de normas protetoras à parte que mais sofria os efeitos das péssimas condições de higiene e segurança no local de trabalho, qual seja, o trabalhador.

Moraes (2009, p. 41) ao analisar o Decreto 3.724 de 15 de janeiro de 1919, que definia a reparação devida aos trabalhadores por acidentes sofridos em duas funções laborais, leciona que a origem da legislação protetiva remonta ao sistema alemão, em que, desde 1884 foi abandonada a consideração da culpa e aceita a do risco profissional. Isto, pois, até aquele momento entendia-se que o trabalhador das grandes fábricas não merecia, em seus sofrimentos e aspirações, a intervenção do Estado, uma vez que a postura "atentaria contra o sacratíssimo princípio da liberdade do trabalho" (MORAES, 2009, p.7).

Posteriormente, a partir da Revolução de 1930, o Estado brasileiro assumiu uma postura intervencionista, marcada pelas políticas públicas e, em consequência, abriu-se caminho à intensificação da regulamentação das relações de trabalho por meio da legislação. A indicada mudança de paradigmas governamentais refletiu na legislação nacional, que passou a tomar rumos distintos dos até então experimentados, com notável afastamento dos modelos econômicos, sociais e culturais escravocratas e patriarcais de uma sociedade agrária, com vistas à industrialização do país (LUZ; SANTIN, 2010).

A sequência histórica do Direito do Trabalho brasileiro persistiu na mesma linha, qual seja, de intervenção estatal com enfoque na proteção ao trabalhador. É o que se pode perceber especialmente na Constituição Federal de 1988 (BRASIL, 1988), que em seu art. $7^{\circ}$ laceou o rol de direitos básicos dos trabalhadores inaugurado na Constituição Federal de 1934 e, desde a promulgação da Constituição Federal de 1988 até os dias atuais, inúmeras foram as normas jurídicas nacionais criadas para a proteção dos trabalhadores, inclusive no que pertine à medicina e à segurança do trabalho. É o que se passa a aprofundar, juntamente com a influência das questões de gênero sobre a matéria. 


\section{SEGURANÇA DO TRABALHO EM UMA PERSPECTIVA DE GÊNERO}

Inicialmente, é importante destacar que gênero difere de sexo biológico. $\mathrm{O}$ corpo e seus traços biológicos, em linhas gerais, são tidos como a referência que aporta a identidade dos sujeitos nos grupos sociais. Isto, pois, ainda que de forma superficial, aparentam revelar o masculino ou o feminino, sem ambiguidades ou inconstâncias. Em consequência, normalmente, deduz-se uma identidade sexual ao indivíduo (LOURO, 2000).

Contudo, tal constatação pode ser (e por vezes é) equivocada, especialmente diante da complexidade dos humanos. Aí reside a grande distinção entre o sexo, ou seja, do caráter biológico que reveste os indivíduos das características binárias do "masculino" e do "feminino", do gênero, que pode ser tido como o conjunto de características pessoais do sujeito, que ultrapassam a diferenciação biológica de homens e mulheres, o qual leva em conta distinções econômicas e sociais, as quais são culturalmente impostas e se traduzem em "um conjunto de normas, valores, costumes e práticas que definem modos de ser, atitudes e comportamentos próprios a homens e mulheres" (CAMPOS; TEIXEIRA, 2010).

De se salientar, entretanto, que a ideia de gênero detém uma diversa gama de conceitos e significações. Por exemplo, para Simone de Beauvoir, pessoas não nascem mulheres, tornam-se mulheres, porque o gênero é construído pelo indivíduo, que pode mantê-lo ou transformá-lo, de maneira volátil e intencional - não necessariamente em decorrência de uma conjuntura social, mas da vontade individual, sem direta ligação sexual (BEAUVOIR, 1973, p. 301).

Nesse aspecto, as convenções sociais institucionalizadas, bem como a legislação trabalhista, seguem o padrão binário originado no postulado da heterossexualidade, exigem uma relação causal entre sexo, gênero e desejo, "seja como um paradigma naturalista que estabelece uma continuidade causal entre sexo, gênero e desejo, seja como um paradigma expressivo autêntico, no qual se diz que um eu verdadeiro é simultaneamente ou sucessivamente revelado no sexo, no gênero e no desejo" (BUTLER, 2003, p. 46-47). Assim, aceita-se como "adequado" que o sexo biológico e a identidade de gênero restem coincidentes, desencadeando o desejo heterossexual esperado, identificado por Butler como heterossexualidade compulsória, ao passo que se aguarda que uma mulher (nascida nesta condição), deva assim se identificar, ou seja, concordar com suas características 
biológicas, possuindo desejo pelo sexo biológico oposto (e desta forma identificado) (BUTLER, 2003). E não só isso, espera-se que essa mulher siga os papéis sociais adequados, inclusive no que diz respeito a profissão ocupada.

O reflexo do gênero, em sua concepção atrelada ao sexo biológico, aparece também nas disposições acerca do meio ambiente de trabalho. Ao analisar regramentos e declarações internacionais que, mesmo não pertencendo ao Direito ambiental ou trabalhista, abordaram o descaso do sistema capitalista com a natureza e a saúde de trabalhadoras e trabalhadores, Feliciano afirma existir uma indissociabilidade ontológica entre o meio ambiente natural e o meio ambiente humano (FELICIANO, 2002. p. 1-49).

Assim, toma-se como referência inicial que o meio ambiente laboral saudável e seguro deve refutar o "entendimento do trabalho enquanto prática assexuada devido à variabilidade da organização técnica e social com base no sexo" (BRITO, 2012. p. 316329). Recusar tal concepção é necessário, pois, significa considerar que os riscos laborais aos quais as mulheres estão expostas muitas vezes são diferentes daqueles que afligem aos homens, o que implica em adotar novas estratégias de prevenção e que seja repensada a maneira que o Direito do Trabalho protege trabalhadores e trabalhadoras.

Acrescente-se a isso a constatação de que o Direito do Trabalho necessita mudar paradigmas quando refere-se à proteção das trabalhadoras, porque há que se superar a ideia de necessidade de tutela das mulheres sob o aspecto da maternidade e da fragilidade. Até porque, tal concepção já é, de per si, uma perspectiva discriminatória, ao passo que coloca a mulher (sexo biológico), em situação de inferioridade. Assim, impõese a prática efetiva da igualdade, de modo que o verbo "proteger" passe a significar, para o Direito do Trabalho, a propalada igualdade material.

Sobre isso, há elementos que levam Rodriguez a considerar a nomenclatura de princípio da igualdade. Primeiro, devido ao seu profundo fundamento constitucional, doutrinário e internacional, que vincula a igualdade à dignidade da pessoa humana. Em segundo lugar, pela condição de fonte de geração de ideias, pela riqueza de suas aplicações e indeterminação dos seus limites (RODRIGUEZ, 2000. P. 440).

Entretanto, desde os anos 1980, quando a flexibilização e precarização do trabalho foram intensificadas pelas políticas econômicas estatais, constata-se o caráter sexuado de tal processo. Atribui-se a isso ao crescimento da participação das mulheres no mercado de trabalho, que ocorreu, majoritariamente, em trabalhos precários e 
expostos a riscos, especialmente naqueles em regime de tempo parcial (part-time), "marcados por uma informalidade ainda mais forte, com desníveis salariais ainda mais acentuados em relação aos homens" (ANTUNES, 2009. p. 160).

Nas décadas seguintes, percebeu-se a reestruturação do capital e sua consequente crise, da qual decorreu o agravamento das condições de trabalho no mundo, especialmente no sentido de adotar como regra geral a precarização do trabalho. Assim, "a terceirização e a informalidade da força de trabalho vêm se constituindo como mecanismos centrais, implementados pela engenharia do capital, para aumentar a exploração do trabalho, valorizando o capital", que, quanto mais intensificado, mais impulsiona a precarização estrutural do trabalho (ANTUNES, 2009. p. 108).

Assim, disserta Saffioti, que o setor informal do mercado de trabalho apresentase como solução para as mulheres com a necessidade de conjugação de afazeres domésticos a uma ocupação que lhes traga renda, uma vez que existe maior grau de compatibilidade entre os serviços prestados de modo precário e a jornada doméstica de trabalho. Dentro dessa lógica, a atividade central das mulheres continuaria ligada à reprodução, enquanto o trabalho remunerado restaria dependente das pressões e obrigações familiares (1985. p. 129-131).

E ao arrolarem as características dessa "divisão sexual do trabalho", Hirata e Kergoat descrevem o surgimento de nomadismos sexuados, derivados da precarização e flexibilização do emprego: nomadismo no tempo, reservado às mulheres, que é expansão do trabalho em tempo parcial ou em domicílio; e o nomadismo no espaço, para os homens, verificado nos trabalhos que exigem deslocamento profissional e maior tempo fora de casa. Observa-se, assim, que a flexibilização se utiliza e reforça as relações de desiguais de gênero, de modo a designar às mulheres os trabalhos em que lhes sobre mais tempo para dedicação à família (2007. p.600).

No decorrer do tempo não se viu mudança de cenário neste ponto. Análises realizadas na primeira década dos anos 2000 sobre o tempo gasto por homens e por mulheres para a execução de tarefas domésticas em diversos países replicam essa assertiva. Tais pesquisas demonstram que mesmo quando a mulher atua no ambiente público, recai sobre ela a sobrecarga do trabalho doméstico, mantendo, assim, "seu papel de dona de casa”. (MADALOZZO; MARTINS; SHIRATORI, 2010, p. 551) 
O trabalho efetuado no ambiente privado, no Brasil começou a ser analisado recentemente e de maneira ainda restrita. Apenas em 2001, com a inclusão de perguntas atreladas ao tema na Pesquisa Nacional de Amostras por Domicílios - PNAD, do IBGE, foi possível verificar a grande disparidade na participação do trabalho doméstico entre homens e mulheres no país. Estudos decorrentes dos dados colhidos via PNAD pelo IBGE entre 2001 e 2005 constataram que além da mulher ser a maior responsável pelas atribuições domésticas, tal realidade não se altera quando ela ingressa no mercado de trabalho (MADALOZZO; MARTINS; SHIRATORI, 2010).

No país, a relação assimétrica dos gêneros masculino e feminino (assim considerados como atrelados ao sexo biológico - pois, esta é a realidade legislativa nacional), quanto à responsabilidade pelo trabalho realizado no ambiente privado, ora tratada, torna-se ainda mais clara ao compararmos a quantidade de horas semanais que homens e mulheres dedicam para tais atividades. Na forma da pesquisa do IBGE de 2006, "as mulheres gastam 25,2 horas semanais no trabalho não remunerado no lar, contra 9,6 horas dos homens" e, embora tenham elas aumentado sua inserção no mercado de trabalho, essa mudança não representa maior igualdade entre gêneros no ambiente doméstico (CAMPOS; TEIXEIRA, 2010, p. 25).

A mesma pesquisa do IBGE ainda indica que essa disparidade de horas dedicadas ao trabalho no ambiente privado se acentua para a mulher na presença de cônjuge no lar, enquanto que para os homens a mesma ocorrência reduz sua dedicação ao trabalho doméstico. Nesse sentido, os dados colhidos pelo Instituto Brasileiro de Geografia e Estatística traduzem a divisão sexual do trabalho no ambiente privado, "onde homens seriam responsabilizados pela manutenção financeira da família, e as mulheres pela manutenção da ordem familiar em termos de produção doméstica e cuidados com outros membros da família (marido e filhos)" (MADALOZZO; MARTINS; SHIRATORI, 2010, p. 557).

Todo este contexto de trabalho realizado no ambiente privado em que se inserem homens e mulheres surte efeitos no ambiente público - assim considerado o espaço social não doméstico, no qual tem lugar o mercado de trabalho (OKIN, 2008). É que, a sistemática familiar, inclusive no que pertine à distribuição de tarefas, é compartilhada na esfera pública, impondo igualmente neste espaço divisões de papéis entre gêneros (CAMPOS; TEIXEIRA, 2010). 
No ambiente público nacional, especificamente no mercado de trabalho, é facilmente detectada a distinção entre homens e mulheres, o que ocorre sob diversos prismas. No aspecto educacional, pesquisas apontam que um número muito mais expressivo de mulheres, do que de homens, acessa e conclui o ensino superior 1 , porém, ocupando nichos profissionais específicos, em áreas caracterizadas como predominantemente femininas, tais como: educação, lazer, saúde e bem-estar social (FCC, 2010). Aliás, esta realidade não é nova no país. Em pesquisa elaborada nos anos 1990 junto às servidoras e às professoras da Universidade Federal de Santa Catarina detectou-se que os empregos ofertados às mulheres eram os "tradicionalmente femininos", relacionados com o mundo doméstico, a exemplo da docência, enfermagem, entre outras (NUNES, 1991).

Ademais, a escolaridade das mulheres não se reflete em benefícios salariais. Neste ponto, pesquisa do IBGE realizada em 2008 identificou que a remuneração das mulheres que possuíam ensino superior completo era, em média, 40\%, inferior a dos homens em mesma condição de escolaridade. (IBGE, 2008)

Sobre o ponto, esclarece Oliveira, que a desigualdade salarial entre mulheres e homens persiste no cenário brasileiro atual, independentemente do setor de atividade em que um ou outro exerçam a sua profissão, advertindo "que a divisão sexual do trabalho e as diferenças de gênero características presentes no sistema capitalista de produção, seguem valorizando e remunerando com salários mais elevados a força de trabalho masculina"(OLIVEIRA, 2016, p. 197-198).

As distinções vão além. Conquanto tenha a mulher conseguido maior inserção no mercado de trabalho, a conquista é apenas quantitativa. A mulher continua relacionada à força de trabalho menos favorecida, ligada ao trabalho doméstico, não remunerado, para a subsistência própria ou da entidade familiar. Conforme pesquisa da Fundação Carlos Chagas, em 2007, 31\% das trabalhadoras ocupavam as posições mais vulneráveis no mercado de trabalho, enquanto que apenas $8 \%$ dos trabalhadores encontravam-se em mesma condição (FCC, 2010).

Dos estudos analisados durante a elaboração desta pesquisa, apenas em um seguimento laboral as mulheres passaram a ter maior destaque, qual seja, o serviço público, em regime estatutário. Em 1985 apenas 16\% dos empregos femininos ocorriam no serviço público sob tal regime, já em 2007, 30\% das mulheres empregadas ocupavam posições 
neste setor (FCC, 2010). Porém, referida adesão de mulheres ao serviço público estatutário, por sua própria natureza, não decorreu necessariamente de mudanças sociais ou políticas públicas. Impõe destacar que o acesso a tais cargos ou funções aconteceu e acontece, por força de regra constitucional $\underline{\underline{3}}$, mediante concurso público, de provas ou provas e títulos, de maneira que a sistemática de contratação não leva em conta o gênero do futuro contratado, mas sua capacidade técnica efetiva.

Assim, resta claro que tanto no ambiente privado, quanto no ambiente público, persistem as discrepâncias entre o trabalho da mulher e do homem. Se no ambiente privado é da mulher o maior papel, no ambiente público é dela a tentativa de inserir-se com melhores condições de labor, pois, a realidade demonstra enraizadas dificuldades a serem superadas - notadamente a repetição da divisão sexual de tarefas precipuamente "do lar" no ambiente não-doméstico.

Vista a estruturação do trabalho no Brasil sob a ótica do gênero ligado ao sexo biológico, que impõe ainda hoje nichos profissionais às mulheres e aos homens de forma distinta, necessário refletir-se acerca das consequências de tal secção laboral às normas de segurança do trabalho, notadamente para as trabalhadoras. É o que este trabalho propõe no tópico subsequente.

\section{AS NORMAS DE SEGURANÇA DO TRABALHO PARA AS MULHERES}

A OIT, em sua Convenção 45, publicada em 1935 e ratificada pelo Brasil em 22.09.1938, vedou o trabalho das mulheres de qualquer idade em trabalhos subterrâneos em minas, salvo em casos de mulheres que ocupassem cargos de direção, prestassem serviços sociais ou de saúde, que para efeitos de formação profissional realizassem atividades no subterrâneo e qualquer outra em exercício de profissão que não seja de caráter manual (artigo $3^{\circ}$ ).

Já em 1944, a Declaração da Filadélfia dispôs em seu item II, letra a, que todos os seres humanos, independente de raça, credo ou sexo, "têm direito a perseguir seu bem estar material e seu desenvolvimento espiritual em condições de liberdade e dignidade, de segurança econômica e em igualdade de oportunidades". Na esteira de tais princípios, a Carta da ONU, de 1945, e a revisão da Declaração dos Direitos do Homem e do Cidadão em 1948, com o lançamento da Declaração Universal dos Direitos Humanos, 
passaram a incluir direitos econômicos, sociais e culturais, como uma nova concepção de direitos humanos fundamentais, sendo relevantes destacar para o presente estudo que desde ali já estava inscrita a igualdade de direitos entre os gêneros e o direito à saúde e ao bem-estar.

Essa mudança de paradigma dos direitos humanos a partir das Nações Unidas trouxe importantes reflexos para a OIT, pois até então as convenções referentes às mulheres tinham como objetivo o fomento da igualdade no trabalho.

Assim, a Convenção 100 da OIT, de 1951, complementada pela Recomendação 90, tratou da igualdade de remuneração entre homens e mulheres para trabalho de igual valor. Da mesma maneira, a Convenção 111 e a Recomendação 111 do mesmo organismo, ambas publicadas em 1958, consagraram o princípio da não-discriminação no emprego e na profissão.

Logo após a Convenção 100 da OIT, de 952, a Convenção 3 foi revista pela Convenção 103 da mesma entidade, a qual estendeu o campo de aplicação das normas de tutela à maternidade às empregadas de setores não industriais, às empregadas agrícolas e domésticas e às mulheres que trabalham em domicílio. Em 1981, a Convenção 156 da OIT dispôs sobre a igualdade de tratamento para homens e mulheres trabalhadores com encargos familiares, prevendo medidas capazes de permitir que trabalhadores $\mathrm{e}$ trabalhadoras tenham igual oportunidade de ingressar, manter-se e progredir em atividade econômica, por meio da promoção de serviços comunitários e de instalações de cuidado para crianças e de amparo à família, como creches e pré-escolas.

A Convenção 156 da OIT apresentou importante evolução na discussão de gênero, compreendendo que a igualdade só é possível se fornecidos instrumentos que diminuam as responsabilidades familiares das trabalhadoras. De outro lado, a restrição ao trabalho noturno das mulheres apenas foi revista pelo Protocolo de 1990 da OIT, relativo à Convenção sobre Trabalho Noturno das Mulheres, que abriu a possibilidade das legislações nacionais introduzirem exceções à proibição do trabalho noturno feminino, desde que consultadas organizações representativas de empregadores e trabalhadores.

Já no Brasil, deve-se atentar que a Constituição de 1937 representou retrocesso ao Direito do Trabalho das mulheres, pois não obstante estar inserto naquela Carta o preceito formal de igualdade (artigo 122) e a garantia à assistência médica e à licença da gestante (artigo 137, alínea 'l'), foram eliminadas da mesma a proibição da diferença 
salarial entre os gêneros e a garantia de emprego à gestante. Ademais, a proibição do trabalho em indústrias insalubres de mulheres e menores foi mantida (artigo 137, alínea ' $k$ '). Soma-se ao quadro reacionário a edição do Decreto-lei no 2.548 de 1940, que estabeleceu a possibilidade de as mulheres perceberem salários inferiores aos dos homens, autorizando redução de até $10 \%$.

Somente em 1943 o cenário legislativo nacional se modifica, a partir da entrada em vigor a CLT, com uma série de dispositivos endereçados às trabalhadoras, merecendo destaque o Capitulo II do Título II, intitulado “da proteção do trabalho da mulher”. Em termos de conteúdo, porém, não houve inovação, tendo sido reproduzidas e colacionadas regras já existentes sobre o tema e organizadas em cinco seções: duração e condições do trabalho, trabalho noturno, período de descanso, métodos e locais de trabalho e proteção à maternidade.

É especialmente relevante para o presente trabalho, o disposto no art. 372 da CLT, que previu a "proteção especial da mulher” já na apresentação do supra referido capítulo, com a ressalva do parágrafo único, que exclui a incidência de tais regras sobre o trabalho das mulheres em oficinas onde sirvam apenas pessoas de sua família e que estejam sob a direção do marido, do pai, da mãe, do tutor ou do filho.

Prosseguia a legislação ao determinar a proibição do trabalho noturno da mulher, assim considerado aquele trabalho executado entre as 22 horas e as 5 horas do dia seguinte. Entretanto, excetuavam-se da limitação ao trabalho feminino as seguintes atividades: empresas de telefonia, radiotelefonia ou radiotelegrafia; enfermagem; casas de diversões, hotéis, restaurantes, bares e estabelecimentos congêneres; postos de direção em trabalhos não contínuos (artigo 379).

O artigo 387 da CLT previu a proibição do trabalho das mulheres em subterrâneos, minerações em subsolo, pedreiras e obras de construção públicas e privadas. Também, impediu o trabalho feminino nas atividades perigosas e insalubres, vedando também o trabalho em serviços que exigissem emprego de força muscular superior a 20 quilos para trabalho contínuo, ou 25 quilos para trabalho ocasional (artigo 390).

Além dessa realidade legislativa disposta à mulher trabalhadora na CLT, há que se vislumbrar o conteúdo das normas regulamentadoras acerca do assunto, pois, impactam as relações laborais no que tange o gênero no meio ambiente do trabalho. Por isso, passa-se a expor a matéria de forma pormenorizada. 
A Portaria do Ministério do Trabalho $\mathrm{n}^{\circ}$. 3214, de 8 de junho de 1978, aprovou 28 Normas Regulamentadoras - NRs - com o objetivo de regulamentar e dar parâmetros mínimos para a saúde e segurança de trabalhadores e trabalhadoras no Brasil. Deste modo consolidou-se a normativa nacional sobre saúde ocupacional e possibilitando a mensuração técnicas dos riscos laborais.

Em sua maioria, as NRs tratam os trabalhadores e as trabalhadoras de modo genérico, porque traçam normas gerais de saúde e segurança ocupacional. Apenas as NRs $15,17,30,31$ e 32 possuem dispositivos especificamente destinados às mulheres trabalhadoras.

Isso ocorre pois, conforme descrito na evolução histórica, as normas referentes à saúde e segurança no trabalho das mulheres, tanto brasileiras quanto internacionais, inicialmente basearam-se em uma série de proibições, que restringiam o acesso das mulheres de forma ampla e irrestrita ao mercado de trabalho, sob alegação de proteção do organismo feminino.

Tais proibições eram, em verdade, fundadas em preconceito e discriminação, e não em uma efetiva preocupação com as trabalhadoras. Amauri Mascaro Nascimento (2012) leciona que, até depois da primeira metade do século XX, a tutela jurídica do trabalho das mulheres considerava quatro aspectos:
a) capacidade para contratar trabalho, submetida a algumas restrições;
b) proteção à maternidade, com paralisações forçadas, descansos obrigatórios maiores e imposição de condições destinadas a atender a sua situação de mãe;
c) defesa do salário, objetivando-se evitar discriminações em detrimento da mulher;
d) proibições, quer quanto à duração diária e semanal do trabalho, quer quanto a determinados tipos de atividades prejudiciais ao organismo do ser humano e que, portanto, devem ser reservadas somente para os homens $(2012$, p.108)

A justificativa para regular especialmente o trabalho feminino era de caráter fisiológico e social. O caráter fisiológico considerava que o corpo das mulheres é diverso do corpo dos homens, possuindo menor resistência física, e devendo ser protegido por conta de sua fragilidade. O caráter social justificava-se como uma defesa da família, pois se faz necessária a proteção das mulheres no seu papel doméstico, para garantir que as ocupações profissionais não impeçam o desempenho de suas tarefas como mãe ou nas lides domésticas. 
Nessa mesma senda, Barros (1995) diz que a necessidade de tal tutela especial das trabalhadoras, em particular as proibições, sustentava-se no argumento da delicadeza e suscetibilidade femininas, aliadas à sua "natural" vocação para o lar:

(...) motivos fisiológicos e de eugenia, ligados, respectivamente, à função reprodutora e ao fortalecimento da raça, para justificar a licença -maternidade e os intervalos destinados ao aleitamento; motivos biológicos, provenientes da debilidade física, capazes de determinar a proibição de trabalhos perigosos, insalubres e as medidas especiais de higiene e segurança; finalmente, razões espirituais, morais e familiares, que a rigor residem 'no resguardo da mulher no lar', utilizadas para justificar a proibição do trabalho extraordinário e noturno. (1995. p. 36)

Assim, conclui-se que as regulações restritivas do trabalho das mulheres, que difundiu-se até o final do século XX, possuíam um caráter muito mais de reprodução da condição de inferioridade da mulher, do que um caráter efetivamente protetivo e igualitário. Porque, serviu para perpetuação da discriminação das mulheres no mercado de trabalho, o que aliás estava explícito quando o Decreto-Lei nº 2.548 , de 1940, permitiu a redução de até $10 \%$ dos salários das mulheres em relação ao dos homens.

Naquela ocasião, o então Ministro do Trabalho, Indústria e Comércio, Valdemar Falcão, alegou que esta medida era necessária, pois, uma vez que existia a obrigação aos empregadores de tomar medidas de higiene e proteção para empregar mulheres, por meio da disponibilização de locais para aleitamento, o trabalho feminino tornava-se naturalmente mais oneroso, de modo a ser cabível a compensação de tais "encargos" por meio da fixação de salários inferiores (BARROSO, 1982. p. 7-11).

Acrescente-se que a proibição do trabalho noturno das mulheres, especialmente na CLT, é predominantemente marcada pelo controle moral das trabalhadoras, bem como pela compreensão de que o labor neste período representava risco à família. Assim, a restrição do labor feminino evitaria o afastamento da mulher do lar e de seu papel social de mãe e esposa:

(...) a mulher que necessitava trabalhar à noite estava sujeita ao julgamento sobre sua retidão moral. Mas não era apenas a moral dessa mulher que estava na mira do legislador. Dificultar a utilização de mão- de- obra feminina nos períodos noturnos era garantir que a operária, se já fosse ou viesse a ser mãe, estaria em casa em horários compatíveis com a criação de filhos. Mas, também, negava-lhe o acesso a uns tantos postos de trabalho. $\mathrm{Na}$ verdade, não havia qualquer explicação científica para se restringir o trabalho feminino noturno, apenas acentuava a divisão sexista das atividades desempenhadas por homens e mulheres. (CALIL, 2000. p. 42). 
Há mais: as situações “excepcionais" previstas pelo artigo 374 não tinham justificativa relacionada à saúde ou à segurança das mulheres, pois eram em verdade uma forma de relegar as mulheres as áreas de trabalho onde elas não seriam concorrentes diretas dos homens. Como exemplo de tais exceções legais, listamos aquelas que "autorizam" o labor tipico e estereotipado como "trabalho feminino": telemarketing, serviços de saúde e cuidado, magistério e trabalho bancário.

De outro norte, a vedação do emprego de mulheres em trabalhos insalubres, perigosos, subterrâneos, em pedreiras ou em obras de construção, baseava-se no argumento da fragilidade do organismo feminino, principalmente em relação à maternidade, uma vez que as mulheres, antes de trabalhadoras, eram vistas como mães em potencial.

Contudo, importante destacar também as palavras de Brumer, para quem

(...) em determinados períodos do ciclo industrial ou em determinadas circunstâncias, como durante as guerras e nos períodos de ascensão dos ciclos econômicos, as mulheres são levadas a participar mais ativamente do mercado de trabalho, mesmo em setores antes considerados como predominantemente masculinos, e que são despedidas ou levadas a retornar às atividades domésticas em outras ocasiões. (...) O Estado, com frequência, toma parte ativa na formulação e implementação (ou anulação) de leis e serviços institucionais que favorecem ou desestimulam a participação das mulheres na força de trabalho. (1988)

Veja-se: se o objetivo da legislação era defender as trabalhadoras contra abusos no trabalho, acabou por corroborar com a bipolarização do emprego feminino, pois, condenou as mulheres pobres, que têm na relação de trabalho o seu meio de sobrevivência, a aceitar empregos cada vez mais precários e menos remunerados, que burlassem as proibições. Assim, o surgimento de dois polos de atividade feminina clivados pela condição de classe foi favorecido: o primeiro abrigando ocupações de má qualidade, informais e sem proteção; e o segundo composto por altos cargos, de elevada formação e altas remunerações, mas que também não está livre da discriminação. (BRUSCHINI e LOMBARDI, 2010. p. 67-104).

Deste modo, pode-se compreender que as normas protetivas concedidas pela lei às mulheres, especialmente acerca das questões afetas a segurança do trabalho foram permeadas pela divisão sexual do trabalho, pela estigmatização do feminino. E, em que pese várias das regras debatidas já tenham restado revogadas, aquelas vigentes tem por base o mesmo raciocínio discriminatório e distante da igualdade material de tratamento 
necessária à consecução de um meio ambiente do trabalho justo e equilibrado às mulheres e aos homens, acima do gênero, e ligada a dignidade de cada ser humano.

\section{CONCLUSÃO}

A proteção à saúde e à segurança no trabalho continua fundada em normas e regulamentos que tratam de trabalhadoras e trabalhadores como uma categoria única e, apesar de que tais normas e regulamentos protejam mulheres e homens de maneira aparentemente isonômica, elas foram definidas a partir de fundamentos sexistas, que consideram o homem como modelo universal de ser humano. Se é a perspectiva de gênero que permite perceber a naturalização das diferenças entre eles, conforme exposto ao longo deste artigo, também é esta visão que permite desvelar as diferenças que encobrem uma falsa neutralidade que, em verdade, se presta à manutenção da desigualdade.

Constata-se que os estudos quantos aos riscos aos quais estão expostos trabalhadores e trabalhadoras, em geral excluem as mulheres, e as especificidades corporais e culturais das trabalhadoras são poucas vezes consideradas nas ações de promoção prevenção de acidentes e doenças ocupacionais. Isso demonstra que profissionais de saúde e segurança no trabalho têm construído o conhecimento da área a partir de uma visão do trabalhador do gênero masculino.

$\mathrm{O}$ resgate histórico apresentado neste artigo, preocupou-se em demonstrar uma concepção tanto das diferenças entre os gêneros em si, até a construção do ideal de maternidade, da fragilidade feminina e da instabilidade das mulheres, e que há argumentos pretensamente científicos que tentam justificar a desigualdade de gênero. Os estereótipos do feminino e masculino naturalizam os papéis de gênero em todos os aspectos da vida, o que gera impacto no reconhecimento do trabalho das mulheres, porque, as invisibiliza no trabalho doméstico não remunerado, e desvaloriza o trabalho produtivo feminino feito no ambiente público. E mais, o cenário impacta no reconhecimento das condições e riscos envolvidos nessas atividades.

O contexto descrito reflete-se no Direito do Trabalho, que contraditoriamente participa do mesmo sistema jurídico que a Constituição Federal de 1988, ao passo que a determinação constitucional da igualdade entre os sexos (e também entre os gêneros), 
acaba por conviver com a tutela especial da CLT ao trabalho feminino, considerado carente de proteção.

E diante da necessidade de tal proteção, acaba a legislação por restringir o acesso de mulheres a determinadas ocupações ou atividades. Se o trabalho for especificamente prejudicial à saúde humana, tanto as mulheres quanto os homens devem ser impedidos de executá-los, exigindo-se que o empregador elimine ou reduza os riscos; caso contrário, trabalhadoras e trabalhadores devem ter a oportunidade de exercê-lo, garantido o acesso a informações e treinamento, além de EPI realmente adequado ao indivíduo.

Conclui-se, respondendo às duas perguntas lançadas, que as normas que visam a proteção das mulheres especificamente no cumprimento de seu papel social feminino trazem efeitos discriminatórios nas oportunidades de emprego e na evolução das carreiras profissionais. Portanto, as normas de saúde e segurança no trabalho para as mulheres precisam focar a proteção baseada na variabilidade humana, o que permite uma isonomia de direitos aos diversos sexos e gêneros, pois, o ambiente laboral somente será seguro quando o for saudável e seguro para trabalhadoras ou trabalhadores, indiscriminadamente, mudando-se a perspectiva de proteção: não são as mulheres que precisam ser excluídas de profissões com risco à saúde ou à sua segurança, mas os riscos é que precisam ser excluídos do ambiente laboral, como efetiva medida de igualdade.

\section{REFERÊNCIAS}

ANTUNES, Ricardo. Os sentidos do trabalho: ensaios sobre a afirmação e a negação do trabalho. São Paulo: Boitempo, 2009.

BARROS, Alice Monteiro de. A Mulher e o Direito do Trabalho. São Paulo, LTR, 1995. p. 36

BARROSO, Carmem. Trabalho e Saúde da Mulher. Revista Brasileira de Saúde Ocupacional, Ministério do Trabalho / Fundacentro, v. 38, n. 10, p. 7-11, abr/mai/jun.1982.

BEAUVOIR, Simone de. O segundo sexo. Tradução E. M. Parshley. Nova Iorque: Vintage, 1973.

BRASIL, Constituição da República dos Estados Unidos do Brasil de 16 de julho de 
1934.

Disponível

em:

<http://www.planalto.gov.br/ccivil_03/constituicao/constituicao34.htm>. Acesso em 16 jul. 2018.

Constituição da República Federativa do Brasil de 1988. Disponível em: $\langle$ http://www.planalto.gov.br/ccivil_03/constituicao/constituicaocompilado.htm〉. Acesso em 16 jul. 2018.

Decreto-Lei n. 5.452, de 10 de maio de 1943: Aprova a Consolidação das Leis do Trabalho. Disponível em < http://www.planalto.gov.br/ccivil_03/decretolei/Del5452.htm>. Acesso em 16 jul. 2018.

. Lei n. 6.514, de 22 de dezembro de 1977. Altera o Capítulo V do Titulo II da Consolidação das Leis do Trabalho, relativo a segurança e medicina do trabalho e dá outras providências. Disponível em< http://www.planalto.gov.br/ccivil_03/LEIS/L6514.htm\#art158>. Acesso em 16 jul. 2018.

Portaria Ministerial n. 3.214, de 08 de junho de 1978. Aprova as Normas Regu- lamentadoras - NR - do Capítulo V, Título II, da Consolidação das Leis do Trabalho, re- lativas a Segurança e Medicina do Trabalho. Disponível em <http://www.camara.gov.br/si- leg/integras/839945.pdf>. Acesso em 16 jul. 2018.

BRITO, Jussara Cruz de; NEVES, Mary Yale; OLIVEIRA, Simone Santos; ROTENBERG, Lucia. Saúde, subjetividade e trabalho: o enfoque clínico e de gênero. Revista Brasileira de Saúde Ocupacional, São Paulo, v. 37, n. 126, p. 316-329, 2012.

BRUMER, Anita. O sexo da ocupação: Considerações teóricas sobre a inserção da mão de obra feminina na força de trabalho. Revista Brasileira de Ciências Sociais, v. 3, n. 8, São Paulo, out. 1988. Disponível em: . Acesso em: 2 jul. 2018.

BRUSCHINI, Cristina; LOMBARDI, Maria Rosa. A bipolaridade do trabalho feminino no Brasil contemporâneo. Cadernos de Pesquisa. n. 110. p. 67-104. julho/2010.

BUTLER, Judith. Problemas de gênero: feminismo e subversão da identidade. Rio de Janeiro: Civilização Brasileira, 2003.

CALIL, Léa Elisa Silingowschi. História do direito do trabalho da mulher: aspectos

históricosociológicos do início da República ao final deste século. São Paulo: LTr, 2000. p. 42.

CAMPOS, Marta Silva; TEIXEIRA, Solange Maria. Gênero, família e proteção social: as desigualdades fomentadas pela política social. Revista Katálysis, Florianópolis, v. 13, n. 1 , p. 20-28, jan. 2010. ISSN 1982-0259. Disponível em: <https://periodicos.ufsc.br/index.php/katalysis/article/view/S141449802010000100003/1 2726>. Acesso em: 03 set. 2018. 
CORRÊA, Sônia. Gênero e saúde: campo em transição. BRUSCHINI, Cristina; UNBEHAUM, Sandra G. (orgs.). Gênero, democracia e sociedade brasileira. São Paulo: FCC: Editora 34, 2002.

CORTÉS, José Maria Cortés Diaz, Seguridad e higiene Del Trabajo, Técnicas de Prevención de Riesgos Laborales 9º ed. Madri, Tébar: 2007.

CRIVELLI, Ericson. Ensaio para uma releitura de Evaristo de Moraes em apontamentos de direito operário. In: SIQUEIRA, Germano; et al. Direito do trabalho: releituras, resistência. São Paulo: LTr, 2017. p. 165-182.

FELICIANO, Guilherme Guimarães. Meio ambiente do trabalho (aspectos gerais e propedêuticos). Revista do Tribunal Regional do Trabalho da $15^{\mathrm{a}}$ Região, [online], v. 20, p. 1-49, 2002. Disponível em . Acesso em: 26 jul.2018.

FCC - Fundação Carlos Chagas. Banco de dados sobre o trabalho da mulher. Coord. BRUSCHINI, C. e LOMBARDI, M. R. Publicado em 2010. Disponível em: <http://www.fcc.org.br/bdmulheres/index.php?area=home> . Acesso em: 03 set. 2018.

HIRATA, Helena; KERGOAT, Danièle. Novas configurações da divisão sexual do trabalho. Cadernos de Pesquisa. V. 37, n. 132, p. 595-609, set./dez.2007.

IBGE - Instituto Brasileiro de Geografia e Estatística. Pesquisa Mensal de Emprego PME. Algumas características da inserção das mulheres no mercado de trabalho. Publicado em: 2008. Disponível em: <http://www.ibge.gov.br/home/estatistica/indicadores/trabalhoerendimento/pme_mulher/ Suplemento_Mulher_2008.pdf> Acesso em: 03 set. 2018.

Pesquisa Mensal de Emprego - PME. Mulher no mercado de trabalho: perguntas e respostas. Publicado em: 08 de maio de 2010. Disponível em: $<$ http://www.ibge.gov.br/home/estatistica/indicadores/trabalhoerendimento/pme_nova/ Mulher_Mercado_Trabalho_Perg_Resp.pdf.> Acesso em: 03 set. 2018.

LUZ, Alex Faverzani da; SANTIN, Janaína Rigo. As relações de trabalho e sua regulamentação no Brasil a partir da revolução de 1930. História, Franca, v. 29, n. 2, p.

268- 278, dez. 2010. Disponível em: <http://www.scielo.br/scielo.php? script=sci_arttext\&pid=S0101-90742010000200015\&lng=en\&nrm=iso $>$. Acesso em 23 jul. 2018.

LOURO, Guacira Lopes. Pedagogia da sexualidade. In LOURO, Guacira Lopes (org.). O corpo educado: pedagogias da sexualidade. 2 ed. Belo Horizonte: Autêntica, 2000. p. 07-24.

MADALOZZO, Regina; MARTINS, Sergio Ricardo; SHIRATORI, Ludmila. Participação no mercado de trabalho e no trabalho doméstico: homens e mulheres têm condições iguais?. Revista Estudos Feministas, Florianópolis, v. 18, n. 2, p. 547, jan. 2010. ISSN 1806-9584. Disponível em: <https://periodicos.ufsc.br/index.php/ref/article/view/S0104026X2010000200015/13666> . Acesso em: 03 set. 2018. 
MELlO, Celso Antônio Bandeira de. Curso de direito administrativo. 20. Ed. São Paulo: Malheiros, 2005.

MORAES, Evaristo de. Os accidentes no trabalho e sua reparação. São Paulo: LTr, 2009, em edição fac-similada do original de 1919.

MOREL, Regina Lucia M.; PESSANHA, Elina G. da Fonte. A justiça do trabalho. Tempo soc., São Paulo, v. 19, n. 2, p. 87-109, nov. 2007. Disponível em: $<$ http://www.scielo.br/scielo.php?script=sci_arttext\&pid=S010320702007000200003\&l ng=pt\&nrm=iso>. Acesso em 24 jul. 2018.

NASCIMENTO, Amauri Mascaro. Curso de Direito do Trabalho. 27 edição. São Paulo: Saraiva, 2012.

NUNES, Lélia Pereira da Silva. Trabalho da mulher - discriminação, realização profissional e realização pessoal (um estudo sobre a mulher na Universidade Federal de Santa Catarina). Revista de Ciências Humanas, Florianópolis, v. 7, n. 10, p. 89-102, jan. 1991. ISSN 2178-4582. Disponível em: <https://periodicos.ufsc.br/index.php/revistacfh/article/view/23755/21321>. Acesso em: 03 set. 2018.

ORGANIZAÇÃO INTERNACIONAL DO TRABALHO. Introductory report: global trends and challenges on occupational safety and health: XIX World Congress on Safety and Health at Work: Istanbul Turkey, 11-15 September 2011. Genebra: OIT, 2011.

OKIN, Susan Moller. Gênero, o público e o privado. Rev. Estud. Fem., Florianópolis , v. 16, n. 2, p. 305-332, Aug. 2008 . Disponível em: <http://www.scielo.br/scielo.php? script=sci_arttext\&pid=S0104-026X2008000200002\&lng=en\&nrm=iso>. Acesso em: 03 set. 2018.

OLIVEIRA, Eleonora Menicucci de. Corpos saudáveis e corpos doentes na nova organização social do trabalho. In: ROCHA, Maria Isabel Baltar da. (org). Trabalho e Gênero: Mudanças, Permanências e Desafios. São Paulo: Editora 34, 2000.p. 237-256.

OLIVEIRA, Olga Maria Bosch Aguiar de. Mulheres e trabalho: desigualdades e discriminações em razão do gênero - o resgate do princípio da fraternidade como expressão da dignidade humana. Rio de Janeiro: Lumen Juris, 2016.

RODRIGUEZ, Américo Plá. Princípios de direito do trabalho. 3 ed. São Paulo: LTr, 2000.

SAFFIOTI, Heleieth Iara. Força de Trabalho feminina no Brasil: no interior das cifras. Perspectivas, São Paulo. v. 8, p. 95-141, 1985. 